\title{
USING GPS DATA FOR MOVEMENT ANALYSIS OF VISUALLY IMPAIRED PERSON
}

\author{
MORAKOT WORACHAIRUNGRUEANG ${ }^{{ }^{*}}$, KUNYAPHAT THANAKUNWUTTHIROT ${ }^{2}$ \& \\ THAMMASAK SONGKA ${ }^{3}$ \\ ${ }^{I}$ Faculty of Humanities and Social Sciences, Suan Sunandha Rajabhat University, Bangkok, Thailand \\ ${ }^{2}$ Fuculty of Industrail Technology, Suan Sunandha Rajabhat University, Bangkok, Thailand \\ ${ }^{3}$ Academic Service Center, Burapha University, Chonburi, Thailand
}

\begin{abstract}
This study aims to present movement pattern of the visually impaired people. The first objective of this study is to present movement information of 50 visually impaired persons who wear GPS trackers during a test as a sampled group. The second objective is to analyze movement of the sampled group. The author gathers the data on the size and location of the Information recorded by the GPS tracker will be downloaded every evening and uses the two-sample $t$ test compares the means of two groups. The researcher does not find gender's influence on distance covered by the sample group, but researcher finds th at gender affects average walking speed of the sample group, as male sample group members can walk faster than the female counterpart.
\end{abstract}

KEYWORDS: Visually Impaired People, GPS Tracker \& T Test

Received: Jun 09, 2020; Accepted: Jun 29, 2020; Published: Jul 23, 2020; Paper Id.: IJMPERDJUN2020428

\section{INTRODUCTION}

Mobility of the handicapped has received increased attention nowadays as the modern society wants more information and planning for the handicapped. The visually handicapped people are an important group in Thai society due to large number and increased likelihood of injury without adequate facilities. The visually impaired people's quality of life is bad and information on their travel outside their residence is few, as information on daily life is considered more important than planning for facility building.

Past research showed that time-space information had positive impact on planning, leading to good result. However, some works had limitations on tools because there was no reliable tool able to record all movements and activities for the entire day. Such information should show details about speed and number of stops as they are important for building understanding about the visually handicapped people's movement.

The Global Positioning System (GPS) is a tool for marking coordinates on the ground that could present both temporal (S) and spatial (m) or distance information. GPS tracking is widely used in many fields such as environment protection, security and healthcare for example tracking the location of a patient with Alzheimer's. Nowadays the GPS' capabilities have vastly improved and been used in logistics and transportation.

This study aims to present movement pattern of the visually impaired people. The first objective of this study is to present movement information of 50 visually impaired persons who wear GPS trackers during a test as a sampled group. The second objective is to analyze movement of the sampled group. 


\section{DATA SOURCE}

\subsection{Study area}

Bangyai is one district of Nonthaburi which has rather many peoples. But in the current situation, the district has been moved into Bangyai City Village which has obtained the growth rapidly from the construction of Kanchanapisek Road and Rattanathibet Road. This has the modern service such as the hospital, the department store, the central market of the province, the government agency, the new housing estate. Hence, the agricultural area mayn't be seen in the city area already. Besides, Bangyai District is the location of the starting point of the electric train in the route from Tao Poon to Bangyai or the Khlong Bang Phai Station. [1]

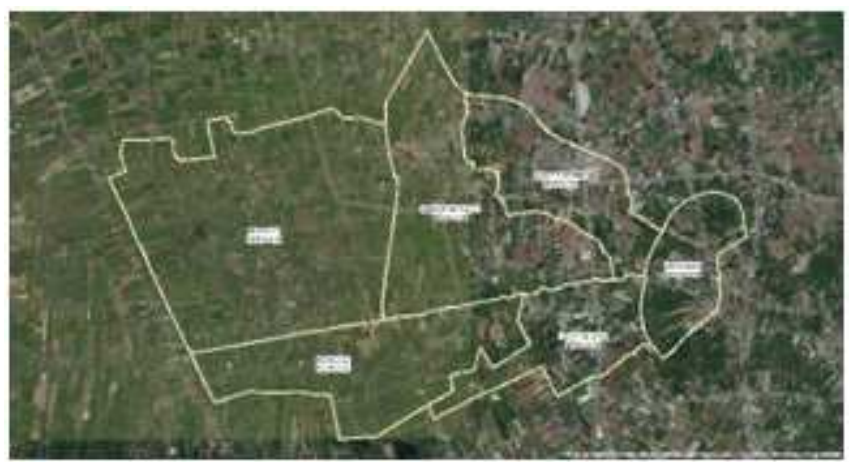

\subsection{Sample Group}

Figure 1: Bangyai district, Nonthaburi Provinec.

Sample group of this study is the visual impairment person, also known as vision impairment or vision loss, is a decreased ability to see to a degree that causes problems not fixable by usual means, such as glasses. This study uses 50 visually impaired persons ( 25 males, 25 females)

\subsection{GPS Tracker}

The author gathers the data on the size and location of the Information recorded by the GPS tracker will be downloaded every evening. Analysis is divided into two parts: the first is analysis of movement, and the second is analysis of time spent on loitering in each spot. Information obtained is in the form of connected dots, each has temporal (S) and spatial/distance (m) information. Such information enables us to know how long the sampled group stay at home or any other place like the hospital or store. It can also tell us about the sampled group's speed. Each dot that represents action by the sample group is called a "node" and a connecting line between two dots is called a "track".

Table 1: Example of movement pattern of male sample member no. 1

\begin{tabular}{|c|c|c|c|c|l|}
\hline Track ID & Duration & Length & Speed & Time & Weekday \\
\hline & & & & & \\
\hline $\mathbf{1 0 1}$ & 43.98 & 4.55 & 5.27 & $25 / 2 / 2018$ & Sunday \\
\hline & & & & & \\
\hline $\mathbf{1 0 2}$ & 52.12 & 5.13 & 5.90 & $26 / 2 / 2018$ & Monday \\
\hline & & & & & \\
\hline $\mathbf{1 0 3}$ & 48.07 & 5 & 5.25 & $27 / 2 / 2018$ & Tuesday \\
\hline & & & & & \\
\hline $\mathbf{1 0 4}$ & 47.40 & 4.86 & 5.16 & $28 / 2 / 2018$ & Wednesday \\
\hline & & & & & \\
\hline $\mathbf{1 0 5}$ & 46.93 & 4.93 & 5.30 & $1 / 3 / 2018$ & Thursday \\
\hline & & & & & \\
\hline
\end{tabular}




\begin{tabular}{|c|c|c|c|c|c|}
\hline 106 & 48.15 & 4.98 & 5.21 & $2 / 3 / 2018$ & Friday \\
\hline 107 & 47.78 & 5 & 5.29 & $3 / 3 / 2018$ & Saturday \\
\hline 108 & 49.65 & 5.04 & 5.09 & $4 / 3 / 2018$ & Sunday \\
\hline 109 & 48.47 & 5 & 5.19 & $5 / 3 / 2018$ & Monday \\
\hline 110 & 42.28 & 4.37 & 5.20 & $6 / 3 / 2018$ & Tuesday \\
\hline 111 & 43.07 & 4.57 & 5.36 & $7 / 3 / 2018$ & Wednesday \\
\hline 112 & 42.35 & 4.38 & 5.20 & $8 / 3 / 2018$ & Thursday \\
\hline 113 & 42.20 & 4.62 & 5.56 & $9 / 3 / 2018$ & Friday \\
\hline 114 & 47.70 & 4.98 & 5.26 & $10 / 3 / 2018$ & Saturday \\
\hline 115 & 51.00 & 5.19 & 5.11 & $11 / 3 / 2018$ & Sunday \\
\hline & 46.74 & 4.84 & 5.22 & & \\
\hline
\end{tabular}

\section{METHODOLOGIES}

\subsection{GPS Tracker}

Movement information of the 50 sample group members is obtained by the wireless GPS logger, which must be carried on the sample group members from 08.00-18.00. The logger can record a node every 10 seconds, with the maximum number of recordable nodes being 130,000 per day. Each node has information on longitude, latitude, time and altitude. The logger is powered by AA batteries and can last for 12 hours without recharge. Information is transferred to the computer every day for 14 days.

Figure 2: The example movement information of the sample group members.

\subsection{The Two-Sample $t$ Test and the $p$ Value}

Currently, the two-sample t test (also called the "independent samples" or "unpaired" $\mathrm{t}$ test) is one of the most used statistical hypothesis tests.[2]

The two-sample t test compares the means of two groups. The sample group, consisting of 50 persons (25 males, 25 females), is selected from a school for the blind. All families of the sample group member give consent to participate in the activity. 
The cut-off for the $\mathrm{p}$ value that determines significance is called the significance level (unfortunately, this term is frequently misappropriated by researchers, who incorrectly use it to describe the p value obtained from the test) or the alpha level. Its value, chosen at the design stage of the study, is usually 0.05 . This means that if $p<0.05$, the null hypothesis is rejected

\section{RESULTS}

In this study has measured walking distance of 50 individuals: 25 males (group A) and 25 females (group B). In this study wants to know if the mean walking distance of male is significantly different from that of females.

In this case, we have two unrelated (i.e., independent or unpaired) groups of samples. Therefore, it's possible to use an independent t-test to evaluate whether the means are different.

Whether the mean of walking distance male is equal to the mean of female?

In statistics, we can define the corresponding null hypothesis $\left({ }_{0}\right)$ and alternative hypotheses $\left(_{1}\right)$ as follow:

- $\quad{ }_{0}$ : male walking distance $=$ female walking distance

- $\quad{ }_{1}$ : male walking distance $\neq$ female walking distance

Table 2: Average walking distance of female and male sample group members

\begin{tabular}{|l|c|c|c|}
\hline & Male & Female & Average \\
\hline & $(\mathbf{k m})$ & $(\mathbf{k m})$ & 3.5 \\
\hline Sunday & 4 & 3 & 5.25 \\
\hline Monday & & 5.3 & 5.35 \\
\hline & 5.2 & & 5.35 \\
\hline Tuesday & & 5.4 & \\
\hline & 5.3 & 5.3 & 5.4 \\
\hline Wednesday & 5.4 & 5.6 & \\
\hline & & & 5.95 \\
\hline Thursday & 5.2 & 5.9 & \\
\hline & & & \\
\hline Friday & 6 & 4.3 & \\
\hline Saturday & 4.2 & & \\
\hline
\end{tabular}

Welch Two Sample t-test

data: mydata\$Distance by mydata\$Gender

$\mathrm{t}=0.41304, \mathrm{df}=42.16, \mathrm{p}$-value $=0.6817$

alternative hypothesis: true difference in means is not equal to 0

95 percent confidence interval:

$-0.37299390 .5649939$

sample estimates:

mean in group 1 mean in group 2 
The sample group mostly has similar movement pattern during the 14-day test period, with male sample members having more average movement than female.

In the result above:

- $\quad \mathrm{t}$ is the $\mathrm{t}$-test statistic value $(\mathrm{t}=0.41304)$

- $\quad \mathrm{df}$ is the degrees of freedom $(\mathrm{df}=42.16)$

- $\quad \mathrm{p}$-value is the significance level of the $\mathrm{t}$-test $(\mathrm{p}$-value $=0.6817)$

- conf.int is the confidence interval of the mean at 95\% (conf.int $=[-0.37299390 .5649939]$

- $\quad$ sample estimates are he mean value of the sample (mean $=5.032,4.936)$.

The p-value of the test is 0.6817 . which is greater than the significance level alpha $=0.05$, we can accept the null hypothesis and rejected the alternative hypothesis. In other words, we can conclude that the mean value of male walking distance is not significantly different the mean value female walking distance.

Another case, Whether the mean of walking speed male is equal to the mean of female?

In statistics, we can define the corresponding null hypothesis $\left({ }_{0}\right)$ and alternative hypotheses $\left({ }_{1}\right)$ as follow:

- $\quad{ }_{0}$ : male walking speed $=$ female walking speed

- $\quad{ }_{1}$ : male walking speed $\neq$ female walking speed

Table 3: Average walking speed of female and male sample group members

\begin{tabular}{|c|c|c|c|}
\hline & $\begin{array}{c}\text { Male } \\
(\mathrm{km} \mathrm{p} \mathrm{H}) \\
\end{array}$ & $\begin{array}{c}\text { Female } \\
(\mathrm{km} \text { p H) }\end{array}$ & $\begin{array}{l}\text { Average } \\
(\mathrm{km} \text { p H) }\end{array}$ \\
\hline Sunday & 4 & 3 & 3.5 \\
\hline Monday & 4.2 & 3.3 & 3.75 \\
\hline Tuesday & 4.3 & 3.3 & 3.8 \\
\hline Wednesday & 4.3 & 3.3 & 3.8 \\
\hline Thursday & 4.2 & 3.15 & 3.675 \\
\hline Friday & 4.3 & 3.2 & 3.75 \\
\hline Saturday & 4.2 & 3.3 & 3.75 \\
\hline
\end{tabular}

Welch Two Sample t-test

data: mydata\$Speed by mydata $\$$ Gender

$\mathrm{t}=4.1081, \mathrm{df}=47.314, \mathrm{p}$-value $=0.0001571$

alternative hypothesis: true difference in means is not equal to 0 
95 percent confidence interval:

0.40115851 .1708415

sample estimates:

mean in group 1 mean in group 2

$4.240 \quad 3.454$

In the result above:

- $\quad \mathrm{t}$ is the $\mathrm{t}$-test statistic value $(\mathrm{t}=4.1081)$

- $\mathrm{df}$ is the degrees of freedom $(\mathrm{df}=47.314)$

- $\quad \mathrm{p}$-value is the significance level of the t-test $(\mathrm{p}$-value $=0.0001571)$

- $\quad$ conf.int is the confidence interval of the mean at $95 \%$ (conf.int $=[0.40115851 .1708415]$

- $\quad$ sample estimates are he mean value of the sample (mean $=4.240,3.454)$.

The p-value of the test is 0.0001571 . which is inferior than the significance level alpha $=0.05$, we can reject the null hypothesis and accepted the alternative hypothesis. In other words, we can conclude that the mean value of male walking speed is significantly different the mean value female walking speed.

\section{DISCUSSIONS}

The researcher does not find gender's influence on distance covered by the sample group, but researcher finds that gender affects average walking speed of the sample group, as male sample group members can walk faster than the female counterpart. This research also discovers some limitations. This research did not compare visually impaired people and normal people.

\section{CONCLUSIONS}

This article aims to present usefulness of the GPS logger in tracking movement of the visually impaired people and recording of spatial and temporal information. Result of this study is not representative of the visually impaired people's movement pattern, but this article aims to present application of a tool for spatial behavior analysis in order to create a more perfect picture.

Despite limited sample size, this study also finds gender is factors in speed which agree of many other works.[3][4][5] For more comprehensive study, future works should include occupation into the primary variable (the visually impaired people). The secondary variable such as spatial sampling should include additional factors like building or land use during a time period. Chi-square could be used to find relationship between gender, age and occupation and building or land use, in order to improve understanding. In-depth interview can be added to investigate causal relationship of factors found in the Chi-square.

\section{ACKNOWLEDGMENTS}

I would like to show deep gratitude to research institute of SuanSunandhaRajabhat University for giving the opportunity and scholarship to do this research. 


\section{REFERENCES}

1. Worachairungreung, M. Thanakunwutthirot, K. and Songka, T. 2019. Using support vector machine models for size of motorcycle taxi terminal in Bang Yai district analysis. In Proceedings of the 8th International Conference on

2. Informatics, Environment, Energy and Applications (IEEA '19). Association for Computing Machinery, New York, NY, USA, 212-216. DOI=https://doi.org/10.1145/3323716.3323750

3. Tracey J. Lamb, Andrea L. Graham, and Aviva Petrie. 2008. t Testing the Immune System. Immunity. 28, 3, 288-292. DOI= https://doi.org/10.1016/j.immuni.2008.02.003.

4. Wang, NIEN-TSAN, Y. L. Chen, and Y. C. Hsu. "Assistive design of cursors for low vision users." Int. J. Commun. Media Stud.(IJCMS) 6 (2016): 1-6.

5. Randi J. Hjorthol, Lena Levin, and AnuSirén, 2010. Mobility in different generations of older persons: The development of daily travel in different cohorts in Denmark, Norway and Sweden. Journal of Transport Geography. 18, 55, 624-633. DOI= https://doi.org/10.1016/j.jtrangeo.2010.03.011.

6. Rajiah, Saraswatee, and Salim Aliraja. "Early Identification and Intervention in Early Years: Preschool Teachers in Mauritius." International Journal of Educational Science and Research (IJESR) 6.3 (2016).

7. Shoval, N., Auslander, G., Cohen-Shalom, K., Isaacson, M. Landau, R.andHeinik, J. 2010. What can we learn about the mobility of the elderly in the GPS era? Journal of Transport Geography. 18, 5, 603-612. DOI= https://doi.org/10.1016/j.jtrangeo.2010.03.012.

8. Guntayuong, C., et al. "Determination of normative values of the Developmental Test of Visual Perception (DTVP-2) in Thai children." International Journal of Medicine and Pharmaceutical Sciences 3.2 (2013): 113-126.

9. R.G. Prins, F. Pierik, A. Etman, R.P. Sterkenburg, C.B.M. Kamphuis, and F.J. van Lenthe. 2014. How many walking and cycling trips made by elderly are beyond commonly used buffer sizes: Results from a GPS study.Health \& Place. 27, 127-133. DOI= https://doi.org/10.1016/j.healthplace.2014.01.012.

10. Ahmed, Ayesha Sultana, and P. Radha Rani. "A Study on Health Problems Among the Elderly Residing in Selected Oldage Homes of Hyderabad City." International Journal of Medicine and Pharmaceutical Science (IJMPS) 8.1 (2018): 19-24. 

